\title{
Shutters Shut and Open: \\ Photographic Theory in Gertrude Stein's Literary Portraits
}

Author: Laure Parkinson

Faculty Mentor: Stephanie Hawkins, Department of English, College of Arts and Sciences

Department and College Affiliations: Department of English, College of Arts and Sciences; Honors College 


\section{Bio:}

Laure Parkinson is an undergraduate scholar and member of the Honors College at the University of North Texas. She is majoring in English with a concentration in literature and minoring in history and French. Her research interests include interdisciplinary studies in literature and visual art theory. She presented her undergraduate thesis at University Scholar's Day in 2012 and hopes to present it elsewhere in the future. She plans to graduate summa cum laude in the summer semester of 2012 as a Distinguished Honors Scholar. After graduation, she will pursue graduate school in American literature. In her free time, Laure maintains a blog dedicated to fashion, literature, and film and works at an energy law firm in Dallas. She is also working on articles for a new magazine dedicated to women that will debut in summer 2012. 


\begin{abstract}
:
This paper investigates how Stein uses photographic theory in the formal construction of her literary portraits in order to create an autonomous work of art and an authentic resemblance to her human subjects. I examine the critical context in which Stein’s portraits first appeared in the art-photography journal, Camera Work, to show the overlapping thematic concerns between photography and literature as artistic mediums in the modernist movement. In addition, I critically analyze two of Stein’s portraits: “Picasso," one of the two portraits published in Camera Work, and her later portrait of the artist, "If I Told Him: A Completed Portrait of Picasso,” to demonstrate how photographic techniques contribute to the immediacy and autonomy of Stein's portraits. Ultimately, while painting and sculpture were the first artistic mediums to explore abstractionism, Stein’s portraits reveal how literature and photography could be justified as art in the modernist movement.
\end{abstract}




\section{Introduction}

Writer, art collector, lesbian, and expatriate living in Paris at the turn of the twentieth century, Gertrude Stein symbolized the revolutionary woman during the advent of modernism. She was one of the most prolific, certainly one of the first, writers of the movement, publishing in a number of genres. The most productive of her works were her portraits, which she wrote of "practically everybody she has known, and written them in all manners and styles” (Stein, The Autobiography of Alice B. Toklas 114). Throughout her writing career, Stein created literary portraits of Matisse, Picasso, and other prominent artists and celebrity figures of the early twentieth-century avant-garde movements. In fact, The Autobiography of Alice B. Toklas, authored by Stein (and not the “autobiographer" herself) was also one of Stein’s experiments with the genre. In total, Wendy Steiner has counted 132 portraits of individuals, excluding the landscapes and still-life pieces that Stein also dubbed "portraiture” (65). Through her medium of choice, she attempted to reconcile problems of representation, perception, and autonomy in art. For Stein, they were the best way of capturing the spirit of modernism.

Stein so radically revolutionized the tradition of verbal portraiture that she claims to have "invented" the genre (Knapp 95). Traditional verbal portraiture relies on “conventional associations”- heroic traits or mythical allusions, for example—-to portray a subject; but in doing so, it creates a "non-individualizing" portrait (Steiner 8, 16); in other words, traditional portraiture fails to evoke the immediacy, or the presence, of the subject, that is central to portraiture. In contrast to traditional portraiture, Stein's portraits convey "no moral or ideational values, no verbal concision or grammatically correct mannered images” (Knapp 95-6). Stein replaces value-laden nouns with pronouns, 
visceral adjectives and verbs with general ones, and refuses description altogether-both physical and psychological (Steiner 6). In doing so, she seeks to create a portrait that does not merely illustrate her subject, but emanates its autonomy and independence. Stein writes portraiture not to describe her subjects, but to give birth to works that assume an individuality of their own; her portraits are meant to be experienced like the presences of the people she seeks to portray. "The thing that is important is the way that portraits of men and women and children are written, by written I mean made. And by made I mean felt” (Stein, “Portraits and Repetition” 165).

Although Stein's portraits are so unconventional as to elicit a response from a New York Globe Critic who described them as “weird,” “unreadable,” and “childish,” (Hapgood 681), they nonetheless retain the essential elements of portraiture. According to Haselstein, despite the portraits' "radical constructivism,” they are nonetheless “grounded in referentiality,” the most fundamental aspect of portraiture (723). In Steiner's words, “Stein [creates] a conception of the individual which both necessitate[s] and for the first time permit[s] imitative literary portraiture, demonstrating a necessary connection between mimetic representation and the individuality of the portrait subject” (45). Stein's ultimate goal is to create a textual portrait that manages to evoke the same autonomy and immediacy as her subject, a sense of individuality that Stein considers “exact resemblance.”

For these reasons, scholarly research has turned to Stein's portraiture as both the focal point of her oeuvre and as a key to understanding her other works. Most of these studies have performed close readings of these portraits by connecting them to Cubism, to the broad context of Modernism, or to Stein's own public pronouncements in her 
popular lectures when she toured the United States in 1934. Indeed, while Steiner and others have demonstrated that Stein appropriated Cubist visual theories, scholarship has yet to explore the relationship between Stein’s portraits and photography.

Stein’s well-documented relationship with avant-garde photographers and the overlapping thematic concerns between her writing and photographic theory suggest that she employed the metaphorical "lens of the camera” to achieve her idea of a portrait's “exact resemblance” to a human subject. Many of Stein’s acquaintances were prolific avant-garde photographers, including Man Ray and Alfred Stieglitz. In fact, Stieglitz published two of Stein’s first portraits, "Matisse” and "Picasso," as the "raison d’être” of the 1912 Special Number of Camera Work (660-1). Additionally, Stein, who was concerned with problems of perception and the modern, would have been greatly interested in photography as both a revolutionary new technological innovation and as a new artistic medium that redefined ideas about time, authentic representation, and the accidental—concepts which Stein explored in her verbal portraiture. Despite writing very little about photography, she undoubtedly considered the implications of the camera in her portraiture, in which issues of authenticity, representation, and referentiality are dominant thematic concerns.

This paper investigates two of Stein’s portraits through photographic theory to better understand Stein’s techniques for accomplishing “exact resemblance” to her subjects in her portraiture. First, I explore the publication Camera Work and issues in photographic theory contemporary to Stein in order to illuminate the art-historical context in which Stein's portraits first appeared. Next, I use this contextual platform to analyze one of her portraits that she published in Camera Work, "Picasso" (1912), to show how 
Stein's concerns about the literary genre are in conversation with photography. Finally, I end my study with an investigation of Stein's second portrait of Picasso, “If I Told Him: A Completed Portrait of Picasso” (1923), to reveal how Stein’s changing ideas about portraiture culminate in a more sophisticated representation of her subject by employing techniques specific to photographic theory. I reveal how Stein’s exploration of photographic theory, particularly in concepts of representation, immediacy, and autonomy, brings Stein's portraiture closer to an authentic resemblance of her human subjects.

\section{Stein \& Camera Work}

The critical context in which Stein’s portraits first appeared, Camera Work, urges the reader to consider the possible thematic relationships between literary portraiture and photography. Stein's decision to debut her portraits in a journal dedicated to artistic photography, instead of introducing them in a literary or even broadly modernist publication, implies that Stein, to some degree, considered her portraits "photographic" in nature. It urges the reader to consider why Camera Work, of all publications, was an appropriate “gallery” for showcasing Stein’s first portraits.

Alfred Stieglitz, editor-in-chief and founder of the journal, released the first issue of Camera Work in 1902. In an effort to draw a distinction between artistic and professional photography, he ironically titled the publication after the term assigned to professional photographers, “camera workers” (Roberts 12). According to Roberts, it was “the first photographic journal to be visual in focus," publishing high quality photographs by photographers of Stieglitz's inner circle, along with “the best possible critical writing” on photographic theory (13-14). The publication dedicated numerous issues to specific 
photographers or schools of photographers (19). Initially, Camera Work, as the name might imply, was reserved exclusively for photography.

By 1910, however, the journal expanded its scope to include reproductions of other modernist art forms (Roberts 18). Trachtenburg marks this transition from pure photography to a broader range of contemporary avant-garde art as "an event signifying the coming-of-age of photography within an already existing system of discourse” (834). He notes that previously, "worry about the legitimacy of photography as an art stimulated the culminating development of Camera Work” (834). Indeed, Stieglitz intimated this concern in the opening statement of the first issue. Titled “An Apology,” it reads:

[Camera Work] is proposed to issue quarterly an illustrated publication which will appeal to the ever-increasing ranks of those who have faith in photography as a medium of individual expression, and, in addition, to make converts of many at present ignorant of its possibilities. (emphasis added, 104)

In other words, from the inception of the journal, Stieglitz strives to incorporate photography into the critical doctrine of visual art, a struggle not only characterized by photography’s identity as a new artistic medium, but by its natural indexicality.

Because of the photograph's inescapable reference to reality, critics considered it subordinate to other artistic mediums, especially in light of the trend toward abstractionism in painting and sculpture. The pervasiveness of this commonplace belief in art criticism is evidenced by the number of articles published throughout the span of Camera Work's fourteen-year existence dedicated to disproving it. In the article "New Tendencies in Art,” published in Camera Work 22 (1908), J. Nilsen Lauvrik recalls the 
general reaction to the photographs at an art exhibit in which modernist photography, painting, and other visual mediums were displayed side-by-side:

And here, too, pictorial photography was shown on a level with paintings and etchings... Many mistook [them] for mezzotints at first glance, only to discover to their amazement and mortification that these were merely photographs they had been admiring.

Not a few remarked [on] the superiority in quality of the [photographic] portraits by Steichen and White, which led one art critic into the error of calling them reproductions of paintings, evidently on the presumption that nothing like [these portraits] could possibly be done with a camera. (104)

Lauvrik’s own emphasis on “merely photograph" and the critics’ error of mistaking them for "reproductions of paintings" betray the popular critical doubt in photography's artistic qualities. Among critics, photography was at best considered a mechanical way of imitating, but not recreating, reality.

In art, this translates into the problem of opacity, the gradation from "transparent" to “opaque” art. Since Plato's distinction between "the image ('copy’)” and "the thing depicted (the 'original'),” fine art has been held to a standard of authenticity in which it must prove its autonomy from its referent (Sontag 154). Because a work of art differs both in essence and substance from its subject, art theorists (including Gertrude Stein) demanded art assume its own independence. By nature, painting and sculpture were more inclined to support this sense of independence that became realized through abstraction, while photography and writing were hindered by their referential qualities. 
Painting, though often representational of reality, is not inherently indexical; a brush stroke, for example, does not inherently signify an object in reality or idea (Steiner 11). It is only through establishing a relationship of brush strokes, color, and other conventions that a painting may come to represent an exterior thing. In other words, paintings exhibit an opaqueness that gives them autonomy because their components are not inherently referential. Because of this, “[w]e don’t see through paintings” (Walton qtd. in Freeland 103). This opaque quality of painting allows it to more successfully abandon any meaning exterior to the work of art itself.

Photography, however, is intrinsically referential of its subject. According to Barthes, "the Photograph...is the absolute Particular" because it "always carries its referent with itself" (5). In other words, we are always looking at a photograph of something existent, whether it has been abstracted through various processes of manipulation or not. Susan Sontag describes photographs as "a trace, something directly stenciled off the real, like a footprint...never less than the registering of an emanation (light waves reflected by objects) -a material vestige of its subject” (154). The process of creating a photograph — the registering of light on a sensitive film to capture a perspective of a real image—directly references, even records, reality.

Similarly, the verbal medium inherently functions as a complex network of signs. According to Steiner, language is symbolic because "words are related to their referents through a socially agreed upon convention” (12). Every word, a composition of arbitrary shapes and sounds, has meaning beyond itself, an external referent. Even in an incoherent sequence of words, each word refers to something. It seems, then, paradoxical for writers and photographers to achieve autonomy, to create an artistic work that is a thing in itself. 
And yet, despite the intrinsic indexicality of both mediums, Gertrude Stein and her contemporaries in photography sought to achieve autonomous, “opaque,” Modernist portraiture.

Considering this difference in artistic mediums in light of modernism, perhaps Stieglitz and Stein, then, published Stein's portraits in Camera Work to draw attention to the two more referential mediums’ capability of artistic autonomy. In the 1912 Special Number issue, Stieglitz lauded Stein’s portraits as the “common denominator of comprehension" and the "Rosetta stone" to the "intellectual and esthetic attitude which underlies and inspires the [modernist] movement” (661). Haselstein explains that the “Rosetta stone” metaphor to Stein’s portraits recognizes "both the familiar and the incomprehensible and show[s] them to be versions of each other” (731). Although I agree with Haselstein’s interpretation, I think Stieglitz’ metaphor begs a deeper level of comparison between Stein's prose and photography. In an avant-garde movement that progressed toward abstraction, Stieglitz wanted to justify the inherently referential art medium’s place in modernism, and the first example of “abstractionism” and nonmimetic representation in these art forms was indeed Stein’s portraiture. In his "Rosetta stone” metaphor, Stieglitz refers to both the artistic (or pictographic) potentiality of Stein's work, while also acknowledging its functionality as referential prose. Thus, using Stein’s portraiture as a “Rosetta stone” for photography, Stieglitz encourages art critics, suspicious of photography's merits, to consider the modernist possibilities of inherently representational art forms. Camera Work, then, served as a platform for photography and writings' entry into an art movement that tended toward abstractionism and non- 
referentiality; and it was Stein’s “Picasso,” alongside "Matisse,” that embodied these new problems about representation and autonomy in inherently indexical art.

\section{“Picasso"}

Stein's first portrait of Picasso that appeared in the Special Number of Camera Work is one of her most examined portraits (Hoffman 164). The portrait's popularity is credited to Stein's well-known, intimate friendship with the artist, making the portrait more accessible to readers and scholars. In addition, this portrait, although still experimental, reads more coherently than many of her other ones. Readers who are unacquainted with Stein's theories about portraiture or Picasso himself can still “make sense” of the text (Walker 83). Without trying to simplify the portrait, Steiner delineates the basic information: "Picasso had a following...[who] knew he was working and bringing something out of himself, [and] the 'something' was 'heavy,' 'solid,' ‘complete,’ and meaningful” (75). She explains, “Even lacking knowledge of Picasso’s painting one would recognize this as some form of creativity activity” (76). In other words, despite the abstracted nouns and concepts, the themes of the portrait are nonetheless clear, and the reader is able to see the relevance of the portrait to the subject. Thus, the text is clearly and justifiably a portrait of Picasso through its thematic relationship to the life of the artist, despite its abstracted references. However, it is predominantly through form that Stein seeks to give her portrait autonomy, creating an “exact resemblance” to Picasso. In fact, Stein's exploration of tense and what she called “mistakes,” dominant formal techniques both related to photographic theory, are two means by which Stein emulates the subject. 
One of the most notable features of Stein's "Picasso" portrait is her use of the past progressive and past perfect progressive tenses, which implies continuous actions in the past sustained for an extended period of time. "Some were certainly following and were certain that the one they were then following was one working and was one bringing out of himself then something” (Stein, “Picasso” 333). She effectively creates a sense that, as we "look" at this portrait of Picasso, we are witnessing a series of continuous, moving actions - working, following, and bringing. The verbs are, in fact, the focal point of the portraits - they dominate the text. In "Poetry and Grammar," Stein explains that verbs are "on the move," and thus, they animate the portrait, giving it an opacity and autonomy that mimics its subject (qtd. in Steiner 59). Although we are looking into the past, signified by “were” and "was," we perceive the "photographic” moment in which actions are taking place.

In Barthes’s Camera Lucida, he explains this time-sense as the photographic noeme, “this-has-been” (79). He explains, “The photograph is literally an emanation of the referent...[that] touch[es] me like the delayed rays of a star” (81). When we look at a photograph, what we see is a "past state," with "state” being the operative term (82). We describe a photograph as a moment “when I was visiting my cousins at the beach,” or “when my sister was five years old and was swinging on the swing set.” Although we are aware that these events took place in the past, we describe them as a continuous past rather than an isolated moment, a single event. The essence of the photograph, and indeed its uniqueness, is the ability for it to invoke a sense of "presence" from a moment that has already occurred. 
Just as the "this-has-been" noeme permits the photograph to be an "emanation of the referent," verb tense in Stein's portraiture similarly creates the effect of the portrait “emanating” the subject. Stein uses the past progressive and past perfect progressive tenses to invoke a sense of a state or condition, an arrested point in time in which the reader examines continuous actions taking place. The auxiliary verbs "was" and "were” imply a past state of being, while the participles, such as "working” or "following” imply incessant movement. Bridgman clarifies that the gerund "at once represents an entity and a continuous action” (qtd. in Steiner 74). This representation of “an entity and a continuous action” is precisely what Stein wanted to achieve in her portraiture because it created the illusion that the portrait was, essentially, an existent thing like her subject.

In addition, Stein values verbs as the most important part of speech because, not only can they animate a portrait, but, according to her, they can "make mistakes” (qtd. in Steiner 59). Stein's use of the accidental was one of the many ways she overturned traditional portraiture norms. Steiner notes that traditional painted and literary portraiture "both habitually conceive of the individual not as being at one arbitrary moment of his existence, but ... beyond the accident of the moment” (9). She concludes, “As a result, the presentation of the subject does not correspond to any actual moment in [the subject's] life, where accidentality and irreverence are omnipresent...so that the portrait represents a mental fabrication and not an existent being immediately perceived” (11). Accidentality permits a more honest representation of a subject because it more honestly represents life. Thus, Stein sees accidents or “mistakes” as a necessary mode to emulating the humanness and authenticity of her subjects, thereby creating a more accurate and autonomous portrait of her subjects. 
In fact, the advent of photography marks the moment that authentic accidents could occur in art. The camera has the ability to capture mistakes because the photographer must briefly relinquish control of the image to the eye of the camera when the shutter is released (Sontag 52-3). The subject of the portrait might blink at the moment of the flash, or, in Lyall Bush’s case, one’s mother might look through the bathroom window in the background as he is photographing his younger brother in the foreground. Bush reflects, "No form invites the random better than photography" (79). Photography's sensitivity to light, its instantaneousness, and the relationship between photographer and camera lend itself to unintended consequences. Sontag writes, "[Photographs] owe their existence to a loose cooperation (quasi-magical, quasiaccidental) between photographer and subject—mediated by an ever simpler and more automated machine” (53). Stein’s employment of “mistakes” in her portraiture cannot be divorced from the context of photography's emergence as an art capable of encountering accidents.

Steiner explains, “'Being something' for a part of speech is thus its ability to be changeable, to create referential or grammatical mistakes” (59). Stein recycles participles ending in “-ing” because they can function as both companions to auxiliary verbs or independently as adjectives or gerunds. In "Picasso" they operate as all three. For example, in the line,

One whom some were certainly following was one working... who had been all his living had been one having something coming out of him... (333) "Were...following” functions as a verb, "living” functions as a noun, and "coming” modifies "something” (333). Although in this instance, the participles' functions are 
clear, Stein believes that these words' flexibility gives them the capacity to be misinterpreted. Indeed, in other passages, the function of the participle is obscure. For example, in the line, "one who was completely charming," the word "charming” can function as either an adjective or a verb (Stein, "Picasso" 333). Picasso ("one”) could be actively charming the "some" who were following him, or Stein could be describing him as a "charming" person. In this phrase, the reader is forced to make an interpretive decision that might result in a "mistake." Stein is fascinated with this concept of the accidental because it gives the words their own autonomy. Regardless of Stein's own intention — whether the word is supposed to function as a verb or an adjective— she relinquishes control of the phrase to the words themselves to be interpreted however the audience happens to read them, giving the work a more human quality.

Stein avoids using nouns in her early portraiture because she believes that nouns cannot make mistakes (Steiner 57). Because nouns carry external associations or have a "marked referential value" - that is, they involve memory and distinct ideas about class or appearance—-the portrait shifts the attention from its own "aesthetic" identity to pure referentiality (Steiner 57-8). In other words, the use of nouns makes the portrait more transparent, that is to say, more referential, rather than opaque. To avoid this, Stein replaces all nouns with pronouns such as "one” or "some," forcing the reader to rely solely on the information provided in the portrait. In this way, she preserves the autonomy and the opaqueness of the portrait while nonetheless preserving the aim of the portrait as a representation of Picasso.

In many ways, Stein’s “Picasso” portrait is also a self-portrait. Stein draws parallels between herself and the subject of her portrait. She writes in her notebooks, 
“Not express yourself like Matisse but be giving birth like Cézanne and Picasso and me” (qtd. in Knapp 99). Indeed, "birth” is one of the motifs of the Picasso portrait: the "something” Picasso is creating in the portrait is "coming out of him” (Stein, "Picasso" 333). In addition, the "something” to which Picasso is giving birth seems to resemble Stein’s own artistic endeavors. Knapp adds: “She saw his work as an autonomous energetic entity in and of itself” (Knapp 99). This “autonomous energetic entity” is precisely what Stein was trying to achieve in her portraiture. This overlap suggests that Stein saw her action of writing of the portrait—an autonomous entity — as analogous to Picasso’s creating a "solid,” “charming,” "perplexing” thing that was perhaps still “coming out of” her, but not yet fully independent.

\section{"If I Told Him: A Completed Portrait of Picasso"}

Stein’s second portrait of Picasso, claiming to be a “completed” one, shows a fuller exploration not only of the artist himself, but of Stein's portraiture. In "Portraits and Repetition," the writer recalls that it was "different from those I had done in the beginning...[it was] less concentrated, [it] moved more” (193). To be sure, the revised portrait of Picasso is more dynamic and abstracted than the first. While some of the same ideas that Stein investigates in "Picasso" shape "If I Told Him,” they are modified by years of experimentation that separate the two portraits. The "Completed Portrait of Picasso,” more than anything, complicates these initial musings on portraiture theory and introduces new ones.

Perhaps the most relevant modification to Stein's portraiture in terms of photography was her introduction of the noun. In "Portraits and Prayers,” Stein recounts how she becomes confronted by the perception of "looking," by the visual aspect of a 
subject (191). She eventually acknowledges that recognizing the "visuality" of "separate, independent objects” is vital to faithfully rendering her subjects, who cannot only be “felt” or perceived through action, but can be seen (Steiner 62). In other words, in order to achieve full autonomy, Stein has to create a face, or perhaps even a body, to attach to the verbs in the portrait; but the nouns that create the visual dimension of the portrait must be independent and, therefore, must avoid conventional association with the subject.

Stein’s misgivings about visual perception as capable of contributing to autonomy are resolved in photographic theory. In Camera Lucida, Barthes describes the photograph's relationship to memory in a way that is related intimately with Stein's concerns about autonomy and immediacy. He writes, "Not only is the photograph never, in essence, a memory...but it actually blocks memory, quickly becomes countermemory” (91). To be sure, the photographic portrait represents, and in many cases mimetically resembles, its subject. But the photograph is also an object in itself that contains all the information we need about the image. The photograph is "never a memory” because, as I mentioned earlier in my discussion, it is a present moment- the “delayed rays” reaching the viewer. It is a preservation of a moment that would otherwise be locked up as a past event—a memory. Barthes explains in an anecdote: “One day, some friends were talking about their childhood memories; they had a number; but I, who had just been looking at my old photographs, had none left” (91). Indeed, the photograph replaces the need for memory. It is a visual entity in which the "nouns" —or objects presented to the viewer-do not need, and in fact refuse, external reference.

Stein comes to the realization that nouns could "very exactly [relate] themselves" to the subject without describing them (“Portraits and Repetition” 191-2). Using nouns 
that had no identifiable reference to the subject, she was able to include a visual element that rendered immediacy without the burden of memory (Steiner 62). In "If I Told Him,” she includes nouns such as “queens,” “curls,” “trains,” and “miracles,” because they have no direct correlation to Picasso-indeed, they have no discernible relationship with each other. Thus, the reader can enjoy the mental images and melodic sounds of the words as she moves through the portrait without having to rely on memory because these words exist purely in the portrait. In this way, the portrait achieves both a fuller autonomy through gaining its own visage and a greater sense of “immediacy” through tangible presence.

Stein also heightens immediacy in her portraits by bringing them into the present. While in "Picasso," Stein uses the past progressive and the past perfect progressive tenses to imply a series of continuous actions in the past, "If I Told Him” is completely invested in the present tense. With the exception of the lines at the beginning that muse over Stein’s hypothetical phrase, “If I told him,” Stein writes exclusively in the present tense, using phrases such as "shutters shut” and "have hold and hear, actively repeat it all” (13, 16). She suggests that the portrait is "happening" at the moment we read it.

As discussed earlier, both traditional visual and verbal portraiture portray the subject as a timeless being by omitting not only the accidental, but real, "arbitrary moments” in the subject's life (9). Thus, Steiner argues, traditional portraiture is “conceptual” rather than "immediate” (10). Stein is overtly aware of this dilemma because, as I have argued, one of the main goals in her portraiture is to create the sense that the subject is present, thereby establishing the portrait’s autonomy, and, by extension, the subject's. 
This ability to render an “arbitrary moment” of a subject's existence in art stems directly from the invention of photography. The camera's capacity to capture the present instantly, to capture the "now," revolutionized the way artists perceived time. In Camera Lucida, Barthes calls this one of the "surprises" of photography (33). Although, as he mentions, many painted portraits attempt to “arrest” important figures in historical moments in time (33), the medium of painting is technically limited because it involves a long process of creation; it cannot immediately recreate a point in time. Additionally, as I discussed, traditional literary and painted portraiture seeks to establish traditional character values, so even a painted historical "moment" is at best a rhetorical exercise that operates on socially established values. On the other hand, "taking advantage of its instantaneous action, the photograph immobilizes a rapid scene in its decisive instant” (Barthes 33). Barthes aptly rephrases this statement later in the book, "Every photograph is a certificate of presence” (87). This uniquely photographic quality of instantaneous creation and the ability to evoke the "present moment” establish an unprecedented sense of immediacy that Stein seeks to recreate in her portraits.

Not only does she achieve this by placing “If I Told Him” in the present tense, but by emphasizing the "moment.” The repetition of "now," "actively,” and "presently” makes the reader aware that she is experiencing the portrait at the present moment in time. These words often stand alone in a line, achieving an almost photographic sense of the present. Each time "now” or "presently” constitutes an entire line, it represents a selfcontained moment in the present. The rapidity with which the reader experiences this "moment" mimics that of the camera shutter capturing an instant. 
Stein’s transition to the present tense in "If I Told Him” authenticates, and indeed modifies, Stein's use of mistakes. Because the portrait is "happening” as we read it, the “mistakes” that we make more closely resemble the chance moments at which accidents occur in photography. As in "Picasso," verbs still dominate the text and occupy various parts of speech. The line "Now to date now to date. Now and now and date the date," is particularly interesting, because it not only plays with the word “date,” alternating between a noun and an imperative verb, but because it also plays with time-sense as well. We understand "now" as the present, but "date” as a noun can refer to a past or future moment; and when it is used as a verb, it occupies the present.

Finally, Stein's modification of the accidental gives way to nouns. Steiner remarks, “She began to see that nouns could make 'mistakes’ too” (61). In "If I Told Him,” Stein does something that seems to contradict all of her previous notions about portraiture. Not only does she use a noun to draw a distinct comparison with the referent of the portrait—she uses a proper noun with powerful historical significance: Napoleon. In the third line, she writes:

If Napoleon if I told him if Napoleon. Would he like it if I told him if I told him if Napoleon. Would he like it if Napoleon if Napoleon if I told him. If I told him if Napoleon if Napoleon if I told him. If I told him would he like it if I told him.

In this line, Stein undoubtedly encourages the reader to compare Napoleon to Picasso, but to make interpretive mistakes in doing so. Given the grammatical constructions of the sentences, the reader cannot be certain if "him” refers to Napoleon or Picasso. For instance, in the first sentence, "him" seems to refer to Napoleon; but the following 
sentence diminishes the reader's certainty: “him” could now easily apply to Picasso, too. In this way, Stein resolves the issue of resemblance by questioning our convictions about the accuracy of the comparison. Additionally, by causing the reader to encounter the accidental, not only with verbs and temporality, but also visually, she finally achieves a self-contained portrait that is an entity acting in the present moment: an immediate, “exact resemblance.”

As is the case with "Picasso," Stein’s second portrait of the painter, titled "If I Told Him: A Completed Portrait of Picasso” is in many respects not only a representation of the artist, but a portrait of Stein's evolving theories about the genre. She uses variants of the phrase "exact resemblance” throughout the text, calling attention to the genre of the work itself. In addition, the motif of trains - the dominant mode of transportation during Stein’s portrait writing — not only appears in this portrait, but in Stein’s published lecture, "Portraits and Repetition.” She writes, “But the strange thing about the realization of existence is that, like a train moving, there is no real realization of it moving if it does not move against something and so that is what a generation does, it shows that moving is existing” (165). Indeed, "If I Told Him,” is not only a completed portrait of Picasso, but also a completed treatise on Stein's theories about portraiture.

\section{Conclusion}

The relationship between Stein's portraiture and modernist photography was not only thematic, but contextual as well. Both verbal portraiture and photography struggled with the same criticism of the modernist art community, which condemned their referentiality. Yet, both mediums were able to eventually justify their place in the modernist movement by gradually resolving these issues. In Stein’s earlier portrait 
"Picasso," she relies heavily on the idea of continuous actions in the past and "mistakes," techniques that both undoubtedly draw upon photographic theory. However, in her later portraits, such as “If I Told Him,” she more successfully achieves her goal of dynamic movement in the present and learns to introduce a visual aspect that does not contradict but enforce her theories of autonomy and immediacy. Indeed, as she comes closer to this fuller realization of an authentic portrait, she draws more obvious parallels between her techniques and photographic theory. She seems to discretely and playfully pay homage to this idea in the line,

Shutters shut and open... Shutters shut and shutters and so shutters shut and shutters and so and so shutters and so shutters shut and so shutters shut and shutters shut and so. (13)

Like the eye of a camera capturing a complete, present, and immediate moment, her portraiture seeks to create a self-contained image as unique as the subject himself. And in many ways, this resembles the evolution of the eye of the camera: from a static moment captured by a picture to a series of “continuous presents” that compose a film. Indeed, Stein’s theory about rendering the present adapts from the photographic moment to the movement embodied by cinematography. In theorizing her use of "repetition,” she uses the metaphor of the individual picture frames that comprise a moving image to describe her invention of the "continuous present," although she contends she had never seen a film when she formulated the idea ("Portraits and Repetition," 176-7). It is my guess that photographic theory of the "moment" encouraged her to move towards these ideas as she resolved problems in portraiture theory. As Stein herself writes: 
The composition we live in changes but essentially what happens does not change. We inside us do not change but our emphasis and the moment in which we live changes. That is it is never the same moment it is never the same emphasis at any successive moment of existing. (“Portraits and Repetition,” 195) Just as Stein's portraits represented the same movement and individuality of the subject she portrayed, her portraits themselves can be viewed as a succession of frames evolving toward a more complete image. Just as the eye of the camera evolves from capturing the arrested moment to a moving image, so too, did Stein's portraits. 


\section{Works Cited}

Barthes, Roland. Camera Lucida: Reflections on Photography. Trans. Richard Howard. New York: Hill and Wang, 1980. Print.

Bush, Lyall. "The Window Girls Move Past Continually: Thoughts on Photography.” The Iowa Review 33.1 (2003): 75-88. Jstor. Web. 16 April 2012.

Freeland, Cynthia. "Portraits in Painting and Photography.” Philosophical Studies: An International Journal for Philosophy in the Analytic Tradition 135.1 (2007): 95109. Jstor. Web. 4 April 2011.

Hapgood, Hutchins. “A New Form of Literature.” Camera Work: The Complete Illustrations, 1903-1917. Ed. Alfred Stieglitz. New York: Taschen, 1997. 681-2. Print.

Haselstein, Ulla. “Gertrude Stein’s Portraits of Matisse and Picasso.” New Literary History 34.4 (2003): 723-43. Jstor. Web. 3 March 2011.

Hoffman, Michael J. "Portraits and the Abstract Style, 1908-1912.” The Development of Abstractionism in the Writings of Gertrude Stein. Philadelphia: University of Pennsylvania Press, 1965. 143-174. Print.

Knapp, Bettina L. "Verbal Portraits: Crosswords, CrossSections (sic), Cross-purposes— Puzzling Logogriphs.” Gertrude Stein. New York: The Continuum Publishing Company, 1990. 95-110. Print.

Lauvrik, J. Nilsen. “New Tendencies in Art.” Camera Work 22 (1908). Camera Work: The Complete Illustrations, 1903-1917. Ed. Alfred Stieglitz. New York: Taschen, 1997. 104-107. Print. 
Roberts, Pam. “Alfred Stieglitz, 291 Gallery and Camera Work.” Camera Work: The Complete Illustrations, 1903-1917. Ed. Alfred Stieglitz. New York: Taschen, 1997. 6-31. Print.

Sontag, Susan. On Photography. New York: Anchor Books, Doubleday, 1973. Print.

Stein, Gertrude. The Autobiography of Alice B. Toklas. New York: Vintage Books, 1990. Print.

--. “If I Told Him: a Completed Portrait of Picasso.” PennSound. Electronic Poetry Center, 2005. Web. 18 April 2012.

--. "Picasso.” Selected Writings of Gertrude Stein. Ed. Carl Van Vechten. New York: Vintage Books, 1990. Print.

--. “Portraits and Repetition.” Lectures in America. 1935. Boston: Beacon Press, 1957. 165-206. Print.

Steiner, Wendy. Exact Resemblance to Exact Resemblance: the Literary Portraiture of Gertrude Stein. New Haven: Yale University Press, 1978. Print.

Stieglitz, Alfred. “An Apology.” Camera Work 1 (1902). Camera Work: The Complete Illustrations, 1903-1917. Ed. Alfred Stieglitz. New York: Taschen, 1997. 104107. Print.

--. “Editorial.” Camera Work Special Number (1912). Camera Work: The Complete Illustrations, 1903-1917. Ed. Alfred Stieglitz. New York: Taschen, 1997. 660-1. Print.

Trachtenberg, Alan. “Camera Work: Notes toward an Investigation.” The Massachusetts Review 19.4 (1978): 834-58. Jstor. Web. 16 April 2012. 
Walker, Jayne L. "Portraits of Artists and Others.” The Making of a Modernist: Gertrude Stein from Three Lives to Tender Buttons. Amherst: University of Massachusetts Press, 1984. 75-100. Print. 